\title{
Erratum to: Nanotech Based Vacuum Insulation Panels for Building Applications
}

\author{
Bjørn Petter Jelle and Simen Edsjø Kalnæs
}

\section{Erratum to:}

Chapter 7 in: F. Pacheco Torgal et al. (eds.), Nano and Biotech Based Materials for Energy Building Efficiency, DOI 10.1007/978-3-319-27505-5_7

Chapter 7 was inadvertently published without the incorporation of the final corrections it is now updated with the corrections both in the chapter and front matter.

The updated original online version for this chapter can be found at DOI 10.1007/978-3-319-27505-5_7

\footnotetext{
B.P. Jelle $(\bowtie) \cdot$ S.E. Kalnæs

Norwegian University of Science and Technology (NTNU), Department of Civil and Transport Engineering, Trondheim, Norway

e-mail: bjorn.petter.jelle@sintef.no

B.P. Jelle

SINTEF Building and Infrastructure, Department of Materials and Structures, Trondheim, Norway 